\title{
Antibiotic Use Pattern in Orthopedics and Traumatology Ward: A 6 Month Survey in A Tertiary Hospital
}

\author{
Stanislaus Gerald Ethelie, ${ }^{1}$ Adi Imam Tjahjadi, ${ }^{2}$ Andri Primadhi ${ }^{3}$ \\ ${ }^{1}$ Faculty of Medicine Universitas Padjadjaran, Indonesia \\ ${ }^{2}$ Department of Biomedical Science, Faculty of Medicine Universitas Padjadjaran, Indonesia \\ ${ }^{3}$ Department of Orthopaedics and Traumatology, Faculty of Medicine Universitas Padjadjaran/Dr. Hasan \\ Sadikin General Hospital Bandung, Indonesia
}

Abstract Objective: To determine and describe the antibiotic use pattern in the orthopedics and traumatology ward of Dr. Hasan Sadikin General Hospital Bandung as a tertiary hospital in West Java, Indonesia.

Methods: A retrospective cross-sectional study using the total sampling method was performed on the medical records of orthopedics and traumatology patients treated using antibiotics during the period of January 1, 2016 and June 31, 2016.

Results: From the 261 subjects who met the inclusion criteria, it was discovered that the most common antibiotics used were in the following order: cefazolin $(54.41 \%)$, ceftriaxone $(21.84 \%)$, and cefotaxime $(10.35 \%)$. Most antibiotics (75.86\%) were given as prophylaxis. Antibiotics were most often administered for $2-3$ days $(42.53 \%)$, intravenously $(97.7 \%)$, and with a dose of $2 \times 1$ gram $(92.16 \%)$.

Conclusions: The most frequently used antibiotics in the orthoaedics and traumatology ward of Dr. Hasan Sadikin General Hospital (RSHS) was

Received: cefazolin, which was mostly used as a pre-surgical antibiotic. The use of

December 12, 2018 third-generation cephalosporin antibiotics as pre-surgical antibiotics is still observed during this study.

Revised:

September 08, 2019 Keywords: Antibiotic, orthopedics, traumatology

Accepted:

October 19, 2019

pISSN: 2302-1381; eISSN: 2338-4506; http://doi.org/10.15850/ijihs.v7n2.1522

IJIHS. 2019;7(2):67-73

\section{Introduction}

Infection is one of the most potentially harmful problems in orthopedics and traumatology wards. Musculoskeletal infection is still one of the main causes of morbidity which may occur even with good and correct antiseptic techniques. ${ }^{1}$ Infection can significantly prolong treatment time, increase treatment costs, and reduce quality of life. Rational use of antibiotics can reduce the risk of infection. ${ }^{2}$ Irrational use of antibiotics can cause

Correspondence:

Stanislaus Gerald Ethelie

Faculty of Medicine Universitas Padjadjaran

Jalan Raya Bandung Sumedang Km. 21

Jatinangor, Sumedang, Indonesia

e-mail: gethelie@gmail.com adverse side effects such as the emergence of antibiotic resistance. ${ }^{3}$ Research conducted in the orthopedics surgical ward of Dr. Kariadi Hospital, Indonesia, in 2015 revealed that the irrational use of antibiotics contributes 53.3\% of the total antibiotic use, while other studies demonstrated the rise of antibiotic resistance in Indonesia. ${ }^{4,5}$

The use of antibiotics in orthopedics ward considerably varies. A survey of 297 members of the orthopaedics trauma association (OTA) in 2015 in the United States showed that the majority of respondents (96\%) use cefazolin as the first-line prophylaxis when fixing closed fractures of long bones. There is still no agreement for the most appropriate use of cefazolin. Most of the respondents (58\%) gave antibiotics one hour before the incision and repeat the dose within 24 hours. Others give antibiotics half an hour or one hour before 
incision without any repeat dose. ${ }^{6}$ Another study conducted on orthopedics patients at Dr. Kariadi Hospital from July to December 2014 showed that ceftriaxone (41.40\%) is the most frequently used antibiotic, followed by cefazolin (38.85\%). ${ }^{7}$ Antibiotic use pattern, such as antibiotic selection, dosage, administration time, administration duration, toxicity, and administration route, considerably varies; hence this study aimed to provide an overview of antibiotic use pattern in the orthopedics and traumatology ward of Dr. Hasan Sadikin Hospital (Rumah Sakit Hasan Sadikin, RSHS) which may be used as a preliminary information for further studies.

\section{Methods}

This was a cross-sectional study on secondary data collected in June-August 2018 obtained from drug prescription in non-computerized medical records of orthopedics patients who used antibiotics in RSHS, Bandung, Indonesia during the period of January 1, 2016 to June 31,2016 . A total sampling approach was used in this study by including all medical records of orthopedics patients who used antibiotics in RSHS. The exclusion criteria were incomplete or lost medical record data, inaccessible data, and patients with tuberculosis as their primary diagnosis.

This study had been approved by the
Research Ethical Committee of Universitas Padjadjaran, Bandung through the letter of approval Number 236/UN6.KEP/EC/2018 and permitted by the Medical Research Ethical Committee of Dr. Hasan Sadikin General HospitalBandungthrough theissuance of Letter Number LB.02.01/X.2.2.1/13207/2018. This study was also acknowledged and approved by the Orthopedics and Traumatology Department of Dr. Hasan Sadikin General Hospital Bandung, Indonesia.

Variables of this study were antibiotic name and type, dosage, administration route, and duration of use. Data were selected and sorted out according to the inclusion and exclusion criteria, then analyzed using descriptive statistics and processed with Microsoft $\AA$ Excel 2016. After that, the data were presented in the form of tables, percentages, and charts to describe the pattern of antibiotic use.

\section{Results}

Of the 23medical records collected and among them 261 met the inclusion and exclusion criteria of this study. Fifty-one records were excluded because the patients did not use antibiotics while another 11 records were excluded because the patients received tuberculosis diagnosis as their primary diagnosis. The flow diagram of the study selection process is summarized in Figure 1.

Orthopedics patients in RSHS from January 1, 2016-June 31, 2016 $(n=323)$

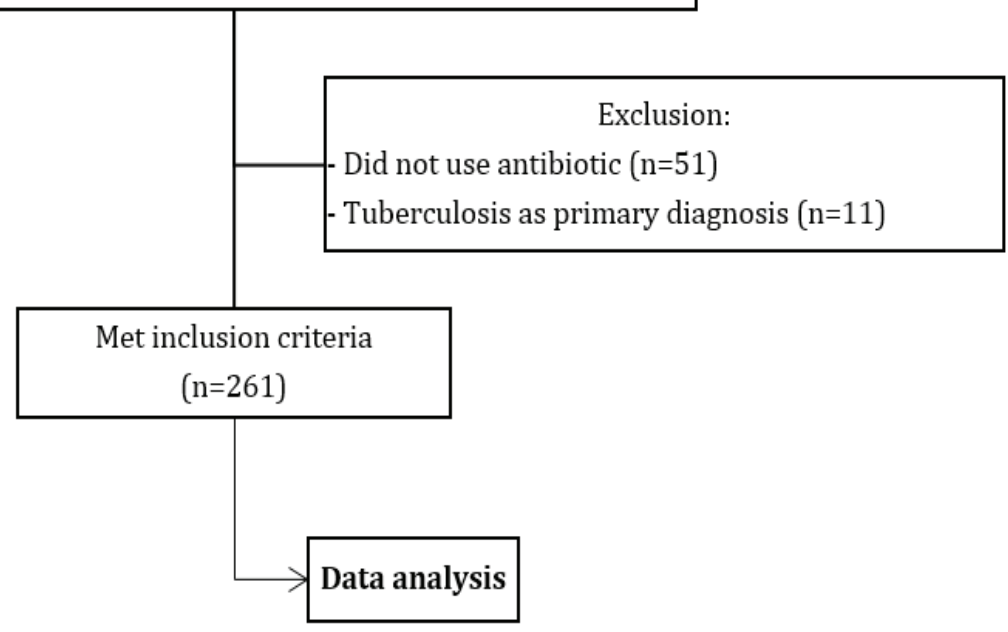

Figure 1 Study of Selection Process Flow Diagram 
Table 1 Patient Demographics

\begin{tabular}{lcccc}
\hline \multirow{2}{*}{ Age Group } & \multicolumn{4}{c}{$\begin{array}{c}\text { Patient } \\
(\mathbf{n = 2 6 1 )}\end{array}$} \\
\cline { 2 - 5 } & $\begin{array}{c}\text { Male } \\
(\mathbf{n = 1 7 1 )}\end{array}$ & $\begin{array}{c}\text { Female } \\
(\mathbf{n = 9 0 )}\end{array}$ & $\mathbf{( n = 2 6 1 )}$ & \% \\
\hline Toddlers (0-5 years old) & 7 & 6 & 13 & 4.98 \\
Children (6-11 years old) & 3 & 1 & 4 & 1.53 \\
Teens (12-25 years old) & 56 & 19 & 75 & 28.74 \\
Adults (26-45 years old) & 59 & 24 & 83 & 31.80 \\
Elderly (46-65 years old) & 41 & 31 & 72 & 27.59 \\
Seniors (>65 years old) & 5 & 9 & 14 & 5.36 \\
\hline
\end{tabular}

Table 2 Antibiotic Use Distribution

\begin{tabular}{|c|c|c|}
\hline Variable & $(n=261)$ & $\%$ \\
\hline \multicolumn{3}{|l|}{ Antibiotic } \\
\hline Cefazolin & 142 & 54.41 \\
\hline Ceftriaxone & 57 & 21.84 \\
\hline Cefadroxil & 3 & 1.15 \\
\hline Cefixime & 3 & 1.15 \\
\hline Cefepime & 1 & 0.38 \\
\hline Cefotaxime & 27 & 10.34 \\
\hline Amikacin & 1 & 0.38 \\
\hline Levofloxacin & 1 & 0.38 \\
\hline Ciprofloxacin & 4 & 1.53 \\
\hline Meropenem & 1 & 0.38 \\
\hline Combination & 21 & 8.05 \\
\hline \multicolumn{3}{|l|}{ Route } \\
\hline Intravenous & 255 & 97.70 \\
\hline$-2 x 1$ gram & 235 & 92.16 \\
\hline -Others & 20 & 7.84 \\
\hline Per Oral & 6 & 2.30 \\
\hline \multicolumn{3}{|l|}{ Type of Therapy } \\
\hline Definitive & 9 & 3.45 \\
\hline Prophylaxis & 198 & 75.86 \\
\hline Empirical & 54 & 20.69 \\
\hline \multicolumn{3}{|l|}{ Antibiotic Replacement } \\
\hline Yes & 39 & 14.94 \\
\hline No & 222 & 85.06 \\
\hline \multicolumn{3}{|l|}{ Culture } \\
\hline Yes & 16 & 6.13 \\
\hline No & 245 & 93.87 \\
\hline
\end{tabular}



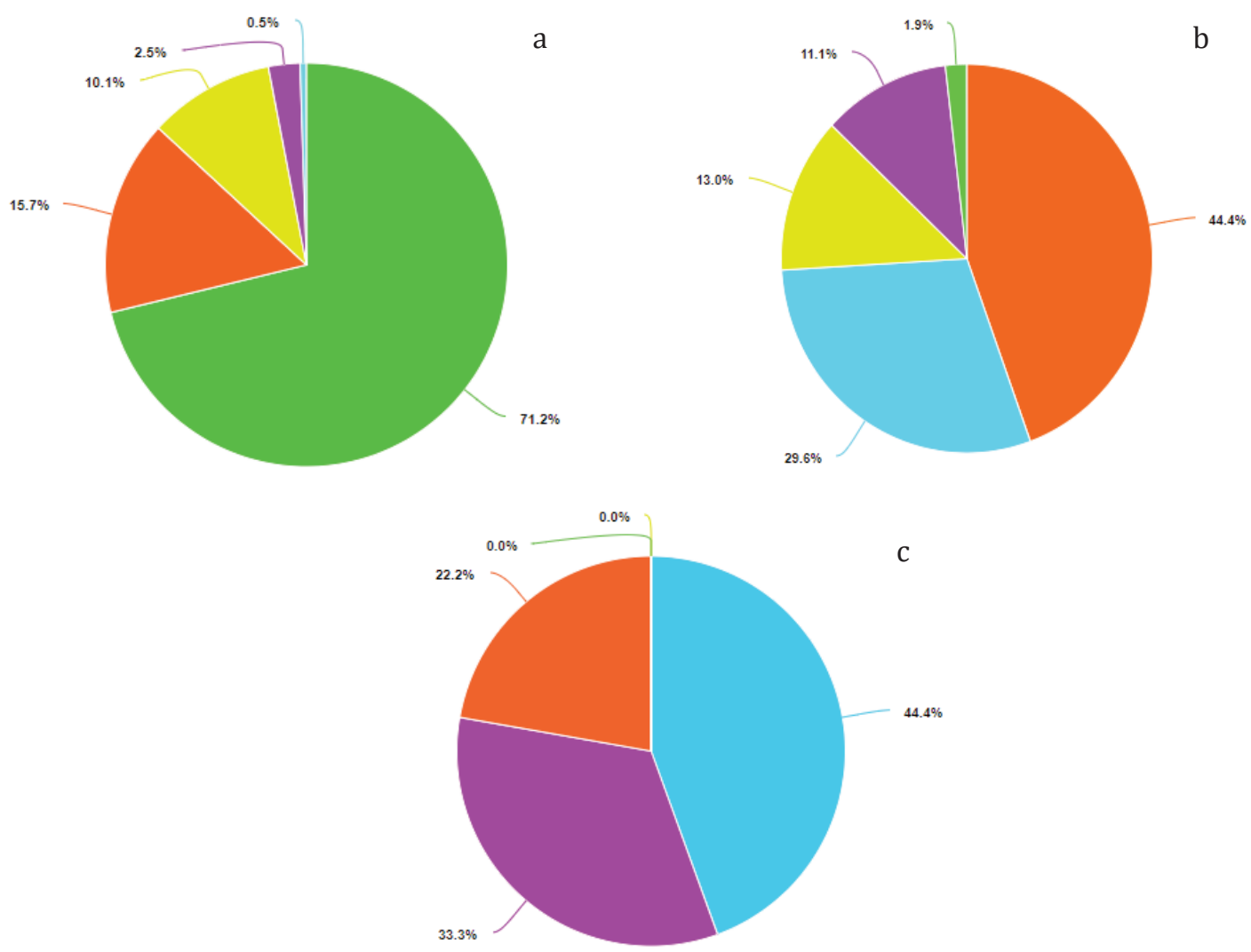

Figure 2 Antibiotics Used in Different Therapies

(a) pre-surgical antibiotics (prophylaxis); (b) empirical therapy; (c) definitive therapy

Patients' age and gender information is listed in Table 1 . Most patients were in the age group of 26-45 years old (31.8\%) and males (65.51\%).

Analysis showed that cefazolin was the most frequently used antibiotic (54.41\%), followed by ceftriaxone $(21.84 \%)$ and cefotaxime $(10.34 \%)$. A total of 21 subjects $(8.05 \%)$ received combination antibiotics. The most common combination was cephalosporin groups with either aminoglycosides or metronidazole. Most subjects (97.70\%) received antibiotics intravenously and $92.16 \%$ of them received $2 \times 1$ gram doses. Of the 261 subjects, 198 subjects (75.86\%) received antibiotics as pre-surgical antibiotics, 54 subjects $(20.69 \%)$ received antibiotics as an empirical therapy, and 9 subjects (3.45\%) received antibiotics as a definitive therapy. Replacement of antibiotic used was performed in 39 subjects (14.94\%). Only a small portion of subjects $(6.13 \%)$ had culture before receiving antibiotics, usually in open fracture and osteomyelitis cases.

The use of antibiotics can be described more specifically based on the type of therapy, i.e. prophylaxis, empirical therapy, and definitive therapy. The most commonly used antibiotics as prophylaxis were cefazolin $(\mathrm{n}=141,71.21 \%)$, followed by ceftriaxone $(\mathrm{n}=31,15.66 \%)$ and cefotaxime $(\mathrm{n}=20$, $10.10 \%$ ) (Figure 2a). In empirical therapy, the most frequently used antibiotics were ceftriaxone $(\mathrm{n}=24,44.44 \%)$, followed by combination antibiotics of 16 data (29.63\%), and cefotaxime with 7 data $(12.96 \%)$ (Figure $2 \mathrm{~b}$ ). The most commonly used antibiotics for definitive therapy are combination antibiotics which are as much as 4 data (44.44\%) and followed by ceftriaxone in 2 data $(22.22 \%)$ (Figure 2c).

Data determined that cefazolin was almost entirely (99.30\%) used as a pre-surgical antibiotic while ceftriaxone was mostly used as a pre-surgical antibiotic (54.39\%) and in empirical therapies (42.10\%). Cefadroxil and 
Stanislaus Gerald Ethelie, Adi Imam Tjahjadi, et al.

Table 3 Antibiotic Use

\begin{tabular}{lcccccc}
\hline Antibiotic & $\begin{array}{c}\text { Prophylaxis } \\
\text { (n=198) }\end{array}$ & $\mathbf{\%}$ & $\begin{array}{c}\text { Empirical } \\
\text { (n=54) }\end{array}$ & $\mathbf{\%}$ & $\begin{array}{c}\text { Definitive } \\
\text { (n=9) }\end{array}$ & $\%$ \\
\hline Cefazolin & 141 & 99.30 & 1 & 0.70 & 0 & 0 \\
Ceftriaxone & 31 & 54.39 & 24 & 42.10 & 2 & 3.51 \\
Cefadroxil & 0 & 0 & 3 & 100 & 0 & 0 \\
Cefixime & 3 & 100 & 0 & 0 & 0 & 0 \\
Cefepime & 0 & 0 & 0 & 0 & 1 & 100 \\
Cefotaxime & 20 & 74.07 & 7 & 25.93 & 0 & 0 \\
Amikacin & 0 & 0 & 0 & 0 & 1 & 100 \\
Levofloxacin & 1 & 100 & 0 & 0 & 0 & 0 \\
Ciprofloxacin & 1 & 25 & 2 & 50 & 1 & 25 \\
Meropenem & 0 & 0 & 1 & 100 & 0 & 0 \\
Combination & 1 & 4.76 & 16 & 76.19 & 4 & 19.05 \\
\hline
\end{tabular}

Table 4 Antibiotic Provision Duration by Type

\begin{tabular}{lcccccccc}
\hline \multicolumn{1}{c}{ Antibiotic } & $\begin{array}{c}\text { Single Dose } \\
(\mathbf{n = 2 1 )}\end{array}$ & $\mathbf{\%}$ & $\begin{array}{c}\mathbf{2 - 3} \text { Days } \\
\mathbf{( n = 1 1 1 )}\end{array}$ & $\mathbf{\%}$ & $\begin{array}{c}\text { 4-7 Days } \\
\text { (n=92) }\end{array}$ & $\mathbf{\%}$ & $\begin{array}{c}>\text { 7 Days } \\
\text { (n=37) }\end{array}$ & \% \\
\hline Cefazolin & 17 & 11.97 & 56 & 39.44 & 52 & 36.62 & 17 & 11.97 \\
Ceftriaxone & 3 & 5.26 & 29 & 50.88 & 20 & 35.09 & 5 & 8.77 \\
Cefadroxil & 0 & 0 & 2 & 66.67 & 0 & 0 & 1 & 33.33 \\
Cefixime & 0 & 0 & 2 & 66.67 & 0 & 0 & 1 & 33.33 \\
Cefepime & 0 & 0 & 0 & 0 & 0 & 0 & 1 & 100 \\
Cefotaxime & 0 & 0 & 14 & 51.85 & 11 & 40.74 & 2 & 7.41 \\
Amikacin & 0 & 0 & 0 & 0 & 1 & 100 & 0 & 0 \\
Levofloxacin & 0 & 0 & 0 & 0 & 0 & 0 & 1 & 100 \\
Ciprofloxacin & 0 & 0 & 1 & 25 & 2 & 50 & 1 & 25 \\
Meropenem & 0 & 0 & 0 & 0 & 0 & 0 & 1 & 0 \\
Combination & 1 & 4.76 & 7 & 33.33 & 6 & 28.57 & 7 & 33.33 \\
\hline
\end{tabular}

Table 5 Antibiotic Provision Duration by Therapy

\begin{tabular}{lcccccccc}
\hline Antibiotic & $\begin{array}{c}\text { Single } \\
\text { Dose } \\
(\mathbf{n = 2 1 )}\end{array}$ & $\mathbf{\%}$ & $\begin{array}{c}\mathbf{2 - 3} \text { Days } \\
\text { (n=111) }\end{array}$ & $\mathbf{\%}$ & $\begin{array}{c}\text { 4-7 Days } \\
\mathbf{( n = 9 2 )}\end{array}$ & $\mathbf{\%}$ & $\begin{array}{c}>\text { 7 Days } \\
\text { (n=37) }\end{array}$ & \% \\
\hline Prophylaxis & 20 & 10.10 & 85 & 42.93 & 72 & 36.36 & 21 & 10.61 \\
Empirical & 1 & 1.85 & 22 & 40.74 & 17 & 31.48 & 14 & 25.93 \\
Definitive & 0 & 0 & 4 & 44.44 & 3 & 33.33 & 2 & 22.22 \\
\hline
\end{tabular}


meropenem were only used for empirical therapies. Cefixime and levofloxacin are exclusively used as pre-surgical antibiotics while cefepime and amikacin were only used in definitive therapies. Cefotaxime $(74.07 \%)$ was mostly used as a pre-surgical antibiotic. However, it was also used in empirical therapies (25.93\%). Ciprofloxacin was mostly $(50 \%)$ used for empirical therapies. Meanwhile, combination antibiotics were most often used in empirical therapies (76.19\%) and definitive therapies $(19.05 \%)$.

Data demonstrated that most antibiotics were administered for 2-3 days $(\mathrm{n}=111$, $42.53 \%$ ) with similar percentages for prophylaxis $(42.93 \%)$, empirical therapy (40.74\%), and definitive therapy (44.44\%).

\section{Discussion}

Data from the study showed that the most frequently used antibiotics in the orthopedics and traumatology ward of Dr. Hasan Sadikin Hospital, Bandung, Indonesia from January to June 2016 was cefazolin $(54.41 \%)$ and ceftriaxone $(21.84 \%)$. This is similar to the findings from the orthopedic ward of Dr. Kariadi Hospital Semarang, Indonesia, in the second half of 2014 (ceftriaxone, 41.40\% and cefazolin, 38.85\%). ${ }^{7}$ Another study on 297 members of the orthopaedic trauma association (OTA) in 2015 in the United States also showed that the majority of respondents $(96 \%)$ use cefazolin as the firstline prophylaxis. ${ }^{6}$

Most antibiotics in this study were used as pre-surgical antibiotics or prophylaxis (75.86\%). Of the 198 uses of antibiotics as prophylaxis, 141 used cefazolin (71.21\%). Cefazolin is the first choice as a prophylactic antibiotic as it is effective for the spectrum of gram-positive bacteria such as Staphylococcus epidermidis, which will not disappear completely when in contact with alcohol. ${ }^{13}$ Staphylococcus epidermidis is an opportunistic normal flora of the skin that can cause infections when there is a trauma to the skin. ${ }^{9}$ Moreover, cefazolin is the most easily tolerated antibiotic whether it is given intravenously and intramuscularly. Cefazolin also has a longer half-life compared to other first-generation cephalosporins; hence, it can be given less frequently. ${ }^{8}$ This is also in accordance with the Indonesian Minister of Health's DecreeNo. HK.02.02/ MENKES/523/2015 on National Formulary which stated that cefazolin should be used for prophylaxis to prevent surgical site infections.
Other antibiotics are considered to be used as prophylaxis if cefazolin is not available or if the patient is diagnosed with a disease with certain antibiotic resistance patterns. It is apparent from this study that the third generation cephalosporins are still widely used for pre-surgical antibiotics although they do not show superiority in preventing surgical site infections (SSIs) compared to the conventional regimens. ${ }^{10}$ of the 63 antibiotics $(24.14 \%)$ used in therapies, 54 (85.71\%) were used in empirical therapies while 9 were in definitive therapies. Ceftriaxone is an antibiotic that is most often used as a therapeutic antibiotic (41.27\%). Third-class cephalosporins, alone or in combination with aminoglycosides, is considered the antibiotic of choice for managing serious infections caused by Klebsiella, Enterobacter, Proteus, Providencia, Serratia, and Haemophilus spp. ${ }^{8}$

Most subjects $(97.70 \%)$ were given antibiotics intravenously with $92.16 \%$ received 2x1 gram doses. Antibiotics given intravenously have a higher bioavailability and a faster effect than oral antibiotics. However, oral antibiotics are more economical and have fewer side effects. ${ }^{8}$ The antibiotic dose is adjusted to the age of the patient. Doses of less than $2 \times 1$ gram were identified in some records for pediatric patients under 12 years of age. Antibiotic doses for children under 12 years should be adjusted to the body weight. ${ }^{12}$

Antibioticswere mostcommonlyprescribed for 2-3 days in this study. The Regulation of the Minister of Health of the Republic of Indonesia No. HK.02.02/MENKES/523/2015 on National Formulary stated that the maximum prescription of antibiotics should be 10 days. This study showed that there were antibiotics that were prescribed more than 10 days in patients with long LOS (length of stay) and repeated medical procedures

Asmallnumber of subjectsused combination antibiotics $(8.05 \%)$ and culture was carried out in $6.15 \%$ subjects. These approaches were applied in cases with infection or had a highrisk for infection, such as in patients with open fractures and osteomyelitis. A combination therapy is given because it can expand the antibacterial spectrum and anticipates antibiotic resistance. ${ }^{11}$

This study has several limitations, including the study period that does not reach one year, making it impossible to capture seasonal diseases. Another limitation is incomplete information in the medical record with regards to antibiotic use, especially information on the purpose of antibiotic use. Therefore, it is 
suggested that an action should be taken by the hospital to make sure that medical record information is complete. It is also necessary to perform a further study with primary data collected from doctors who prescribe the antibiotic to gain a more indepth insight on the antibiotic use pattern.

Cefazolin is the most frequently used antibiotic, followed by ceftriaxone and cefotaxime, in patients in the orthopedics and traumatology ward. Antibiotics are commonly given intravenously, $2 \times 1$ gram, as prophylaxis. Cefazolin is the most commonly used antibiotics for prophylaxis before surgery; however, third-generation cephalosporin antibiotics, such as ceftriaxone and cefotaxime, are still used in a small number of cases.

\section{References}

1. Fleischman AN, Austin MS. Local Intra-wound Administration of Powdered Antibiotics in Orthopedics Surgery. J Bone Jt Infect. 2017;2(1): 23-8.

2. Jenks PJ, Laurent M, McQuarry S, Watkins R. Clinical and economic burden of surgical site infection (SSI) and predicted financial consequences of elimination of SSI from an English hospital. J Hosp Infect. 2014;86(1):2433.

3. Frieri M, Kumar K, Boutin A. Antibiotic resistance. J Infect Public Health. 2017;10(4): 369-78.

4. Susilo D, Priambodo A, Lestari ES. Kualitas Penggunaan Antibiotik pada Kasus Bedah. 2015;4(4):618-25.

5. Hadi U, Qiptiyah M, Paraton H. Problem of
Antibiotic Use and Antimicrobial Resistance in Indonesia : Are We Really Making Progress ? Indones J Trop Infect Dis. 2013;4(4):5-8.

6. Gans I, Jain A, Sirisreetreerux N, Haut ER, Hasenboehler EA. Current practice of antibiotic prophylaxis for surgical fixation of closed long bone fractures: a survey of 297 members of the Orthopedics Trauma Association. Patient Saf Surg. 2017;11(1):2.

7. Haryanto A, Priambodo A, Lestari ES. Kuantitas penggunaan antibiotik pada pasien bedah ortopedi rsup dr. kariadi semarang. 2016;5(3):188-98.

8. Brunton L. Goodman \& Gilman's The Pharmacological Basis of Therapeutics. 12th ed. McGrawHill; 2011.

9. Otto M, Ph D. Staphylococcus epidermidis the "accidental" pathogen. NIH Public Access. 2010;7(8):555-67.

10. Liu W, Christoph M, Groen RJM, Michael C, Grundmann H. Third-generation cephalosporins as antibiotic prophylaxis in neurosurgery: What's the evidence?. Clin Neurol Neurosurg. 2014;116:13-9.

11. Ahmed A, Azim A, Gurjar M, Baronia AK. Current concepts in combination antibiotic therapy for critically ill patients. Indian J Crit Care Med. 2014;18(5):310-4.

12. WHO. Antibiotic Dosing for Children : Expert Recommendations For Children Ages 2 months to 12 years. 2017.

13. Adebayo A, Parikh JG. Shifting trends in in vitro antibiotic susceptibilities for common bacterial conjunctival isolates in the last decade at the New York Eye and Ear Infirmary. 2011;111-9. 